\title{
JUIZADO ESPECIAL CIVEL: SUPERANDO O MITO DE SÍSIFO
}

\author{
Francieli Trevisan De Nardi ${ }^{1}$ \\ Michele Romero da Costa ${ }^{2}$ \\ Pietro Toaldo Dal Forno ${ }^{3}$
}

\begin{abstract}
RESUMO: Este trabalho tem o objetivo de apresentar a importância da promulgação da Lei 9099/95 como um órgão inovador e que propicia um maior acesso à justiça pelos seus jurisdicionados. Para tanto, fez-se uma relação entre os Juizados Especiais Cíveis e Mito de Sísifo, como uma alusão a persistência no sentido de buscar uma satisfação aos anseios de uma sociedade descrente com a justiça. Dessa forma, pretende-se mostrar a necessidade do direito processual não poder se afastar do material, o que, infelizmente, vem ocorrendo, na busca pela autonomia e independência destes institutos.
\end{abstract}

PALAVRAS-CHAVE: Juizado Civil Especial, Sísifo, acesso à justiça.

\section{Juizado Especial Cível: surpassing the Myth of Sisyphus}

\begin{abstract}
This work has the objective to present the importance of the promulgation of Law 9099/95 as an innovative agency and that it propitiates a bigger access to justice for its jurisdicionados ones. For in such a way, a relation between the Courts became Special Civil court jurisdiction and Myth of Sísifo, as a allusion the persistence in the direction to search a satisfaction to the yearnings of an unbelieving society with justice. Of this form, it is intended to show the necessity of the procedural law not to be able to move away itself from the material, what, unhappyly, it comes occurring, in the search for the autonomy and independence of these justinian codes.
\end{abstract}

KEY-WORDS: Civil Special Court, Sisifo, Access to justice.

\footnotetext{
${ }^{1}$ Acadêmica do $7^{\circ}$ semestre do curso de Direito da UFSM. ftdenardi@ig.com.br

${ }^{2}$ Acadêmica do $7^{\circ}$ semestre do curso de Direito da UFSM. michelerc21@ hotmail.com

${ }^{3}$ Acadêmico do $5^{\circ}$ semestre do curso de Direito da UFSM. pietrot@bol.com.br
} 


\section{Introdução}

O direito processual tem, cada vez mais, se afastado do direito material, de forma que se apresenta, atualmente, como um instituto demasiadamente formalista e engessado. Como conseqüência disso, a tramitação dos processos delongou-se de maneira absurda e inaceitável para a sociedade contemporânea. É nesse contexto de insatisfação que surgem os Juizados de Pequenas Causas, os quais, posteriormente, dão origem aos Juizados Especiais Cíveis. Estes têm por objetivos principais uma prestação jurisdicional célere e a composição amigável dos conflitos, atuando para isso, com matérias de menor complexidade e cujos valores não excedam 40(quarenta) salários mínimos nacionais.

Com base na pesquisa bibliográfica realizada, procurou-se analisar, na primeira parte do trabalho, a relação entre a mitologia grega, tendo como inspiração o Mito de Sísifo e a Lei 9099/95. Posteriormente, fez-se uma abordagem geral desde a Constituição Federal de 1988 até a promulgação da Lei que instituiu os Juizados Especiais Cíveis.

$\mathrm{Na}$ segunda parte da pesquisa, objetivou-se explorar os princípios adotados pela Lei 9099/95, o que possibilitou percebermos a contribuição deste instituto legal para o avanço do Direito Brasileiro. Isso é facilmente notado na medida em que procedimentos formalistas são substituídos pela simplicidade e celeridade do processo, bem como pela busca em aproximar o direito material do processual, de modo que este cumpra com seu objetivo, qual seja tutelar os direitos previstos naquele.

Posteriormente, analisou-se a necessidade de aperfeiçoar-se, constantemente, o instituto dos Juizados Especiais Cíveis, suprindo-lhes as falhas que ainda precisam ser sanadas para uma melhor tutela jurisdicional.

Enfim, pôde-se perceber com o presente trabalho que os Juizados Especiais Cíveis surgiram com a missão de realizar o sonho de justiça, que segundo Kelsen é o sonho mais formoso da humanidade. Sonhemos, portanto, com essa nova feição da bondade humana levada a efeito pelos juízes; sem desconhecer, contudo, as inúmeras dificuldades e carências enfrentadas, valorizando, assim, a persistência na busca de soluções para melhor atender aqueles que necessitam. 


\section{O Mito de Sísifo e o surgimento dos Juizados Especiais Cíveis}

\subsection{Mito de Sísifo}

Sísifo, na mitologia grega, era considerado o personagem mais astuto de todos os mortais. Governou Corinto por vários anos e foi tido como um dos maiores opositores dos deuses gregos, restando, por conta disso, eternamente castigado.

Segundo a mitologia, Egina, filha do deus-rio Esopo, possuía uma beleza encantadora, despertando em Zeus o interesse em raptá-la, a fim de ter para si toda a sua formosura. Com o desaparecimento de Egina, Esopo foi procurado por Sísifo, que lhe prometeu contar quem havia raptado sua filha, desde que o mesmo fornecesse água para a cidade de Corinto.

Zeus, quando soube da traição de Sísifo, enviou-lhe Tanatos a fim de que este o conduzisse ao mundo subterrâneo. No entanto, quem lá permaneceu, devido à astúcia de Sísifo, foi o enviado de Zeus, impossibilitando, desse modo, a morte de qualquer pessoa na terra, prejudicando, assim, o reinado de Hades, deus do mundo inferior.

Pretendendo restabelecer a ordem natural, Ares, deus da guerra, libertou Tanatos. Com isso, Sísifo fez com que sua esposa prometesse que jamais iria enterrá-lo e exporia seu cadáver numa praça pública, o que possibilitaria ao mais astuto dos mortais ludibriar por mais uma vez os grandes deuses. Assim, Sísifo alegou à Hades que necessitava voltar à Terra para prestar a seu cadáver as oferendas de costume, sendo que, somente depois disso, poderia considerar-se efetivamente morto. Desse modo, Sísifo conseguiu permanecer por mais algum tempo no mundo dos vivos, até que a paciência de Zeus esgotasse. Então, este resolveu enviar-lhe Hermes para conduzi-lo ao reino das sombras, colocando fim a malícia do engenhoso mortal.

Lá chegando, Sísifo fora castigado, por toda a eternidade, a rolar uma grande pedra de mármore até o cume de uma montanha, sendo que ao alcançar o topo da montanha, a pedra novamente retornava ao ponto de partida, transformando todo seu trabalho em algo inútil e sem esperança.

\subsection{A criação dos Juizados Especiais Cíveis}

Antes mesmo do advento da Constituição da República de 1988, já havia a preocupação com a viabilidade da promessa de acesso à justiça. O processo de conhecimento na Justiça Comum revelava-se insatisfatório, uma vez que as solenidades e os ritualismos delongavam demasiadamente o curso do processo até a obtenção de uma resposta judicial. Nesse sentido, 
merece destaque a iniciativa da Coordenação do Programa Nacional de Desburocratização, que percebeu a inadequação da estrutura judiciária para dar atendimento às causas de menor valor, que embora em grande número, não eram pleiteadas, em face da absoluta obstrução do acesso ao judiciário.

Em 1984, foi criada a Lei 7244, que instituiu os Juizados de Pequenas Causas. Tal diploma legal tratava-se de um procedimento que visava a uma maior celeridade e simplicidade, respeitando o devido processo legal. Assim, o sucesso obtido com os Juizados de Pequenas Causas inspirou o art. 98, I, da atual Constituição, ampliando a esfera de abrangência e atuação daqueles. Posteriormente, foi criado, com a Lei 9.099 de vinte e seis de setembro de 1995, os Juizados Especiais, os quais introduziram na órbita processual brasileira um sistema revolucionário de aplicação da Justiça. Frente a isso, obteve-se a superação de alguns obstáculos que impediam o efetivo acesso ao sistema judiciário.

Esse novel diploma legal tem como princípios basilares a oralidade, simplicidade, informalidade e economia processual, de modo que o órgão sub judice possibilitou o alcance da tão almejada celeridade no tratamento de litígios em nossa sociedade, ultrapassando o rigorismo formal e aproximando a Justiça do cidadão comum.

\subsection{Mito de Sísifo e Juizado Especial Cível}

Comparando o advento dos Juizados Especiais Cíveis com o mito de Sísifo, pôde-se constatar que, assim como Sísifo teve a coragem de enfrentar o poder dos deuses, a Lei 9099/95 buscou, de certa forma, defrontar-se com o paradigma dominante da ciência processual, de forma que procurou aproximar as questões de direito material e processual. Diante disso, constatou-se que a severidade do castigo imposto a Sísifo transformava seu trabalho em algo inútil e sem esperança, no qual se quer era possível ver o homem atrás da imensa pedra. De forma semelhante, tem a ciência processual se esforçado para criar conceitos, a fim de obter uma total autonomia primando pela forma em detrimento do conteúdo e distanciando o direito material do direito processual, esquecendo-se, com isso, de sua verdadeira função, qual seja, a da satisfação das pretensões do direito material.

Diante disso, surgiu a Lei 9099/95, a qual aproximou o direito material do direito processual suprindo o demasiado formalismo existente, o que possibilitou um maior acesso a

prestação jurisdicional. Assim, pode-se dizer que os Juizados Especiais Cíveis têm concentrado seus esforços em uma nova perspectiva de trabalho, primando pela efetivação de 
seus critérios norteadores, bem como pela celeridade na tutela jurisdicional, superando, dessa forma, a missão estéril e sem esperança de Sísifo.

\section{Benefícios trazidos com o Juizado Especial Cível}

Com o advento da Lei 9.099/95, os cidadãos foram contemplados com uma gama de benefícios, os quais estão diretamente ligados aos princípios norteadores desta Lei positivados no $\operatorname{artigo} 2^{\circ}$, conforme se demonstrará a seguir:

\subsection{Princípio da Oralidade, informalidade e simplicidade}

Primeiramente, cumpre ressaltar que os Juizados Especiais Cíveis surgiram não apenas com o intuito de proporcionar o acesso ao judiciário às pessoas menos favorecidas economicamente, mas também solucionar as causas de menor complexidade de forma mais célere, a fim de possibilitar uma efetiva prestação jurisdicional às partes que litigam. Diante disso, constata-se, por exemplo, que o pedido requerido pelas partes poderá ser fornecido por escrito ou oralmente, o que contribui não apenas para acelerar o ritmo do processo, mas também para obter uma resposta num tempo razoável, cumprindo assim, a determinação prevista no art. $5^{\circ}$, inc. LXXVIII da Carta Magna.

Também, pode-se referir que os princípios da simplicidade e informalidade são instrumentos que auxiliam a tramitação dos processos de forma mais ágil, de sorte que os pedidos deverão ser formulados de maneira simples e em linguagem acessível. Ainda, em função desses princípios, não será pronunciada nulidade que não tenha causado prejuízo às

partes, bem como todas as provas, mesmo que não requeridas previamente, serão produzidas em audiência. Desse modo, constata-se que os princípios referidos contribuem de forma ímpar para a tão sonhada celeridade e economia processual.

\subsection{Economia processual e celeridade}

Os Juizados oferecem a quem busca sua tutela uma maior agilidade e eficácia para a solução dos litígios, sem violar, contudo, o Princípio do Devido Processo Legal. No mesmo sentido, as controvérsias submetidas ao Juizado proporcionam um menor dispêndio econômico às partes, uma vez que é facultado, às causas inferiores a vinte salários mínimos, a contratação de advogado; bem como é dispensado o pagamento de custas para o ajuizamento das ações. 
Ademais, o rito desse órgão privilegia a concentração dos atos processuais, possibilitando, por exemplo, em apenas uma audiência compor o conflito, ou instruir o processo.

Outrossim, é fundamental referir que para a redução de gastos necessita-se, igualmente, minimizar a quantidade de atos processuais. A exemplo disso, os prazos previstos na Lei 9099/95 são reduzidos, sendo admitido apenas uma espécie de recurso no lapso temporal de 10 (dez) dias.

\subsection{Integração entre acadêmicos, Poder Judiciário e comunidade}

O crescimento da interação entre acadêmicos e o Poder Judiciário é inquestionável, pois, através de trabalhos voluntários, aqueles auxiliam para que os Juizados Especiais atendam, de forma célere e efetiva, as demandas propostas pela sociedade. Diante disso, não se pode olvidar da importância dos conciliadores, em sua maioria estudantes do curso de Direito, haja vista que estes contribuem para um aumento da capacidade de trabalho dos juízes, além de se mostrarem pessoas hábeis na arte de conter os ânimos dos litigantes, visando a uma composição amigável da lide.

Apesar dos inúmeros benefícios trazidos com a Lei dos Juizados, muitas são as críticas advindas, principalmente, de operadores do Direito apegados ao rigorismo formal, os quais vêem os Juizados como um órgão com fragilidades estruturais. Ainda que pesem as posições desfavoráveis e, mesmo admitindo-se que os Juizados, como uma construção humana que é, apresentam falhas, estas, no entanto, podem ser aprimoradas e constantemente atualizadas, segundo as necessidades da sociedade. Tem-se, porém, como indubitável a sua contribuição para o alargamento do acesso à justiça e a aproximação do cidadão comum à tutela de seus interesses.

\section{A necessidade de aperfeiçoamento do Juizado Especial Cível}

A prática demonstra que os Juizados Cíveis apresentam inúmeras dificuldades e deficiências. Diante disso, espelhando-se na visão positiva do mito de Sísifo, qual seja, a persistência em dar a pedra o movimento ascendente, fazendo deste o seu objetivo, por ele trabalhando e lutando, sem cansar ou desistir, transforma esta sina em sua arte, a fim de manter sua consciência eternamente viva. Os estudiosos do Direito têm o dever de continuarem lutando por uma justiça que se aproxime cada vez mais do cidadão e prime pelos princípios adotados pela Lei 9099/95 (oralidade, simplicidade, informalidade, economia processual e ce- 
leridade), para que esta conquista não fique apenas no papel, mas, principalmente, que seja prática diária no sistema judiciário, estendendo quiçá seus princípios a outros órgãos.

Nesse escopo, são de grande importância as críticas aos Juizados Especiais Cíveis. Entretanto, para o avanço do sistema não bastam apenas críticas, é necessário e imprescindível que com elas despontem, também, as sugestões a fim de contribuir para o aprimoramento dos procedimentos. Da mesma forma, de nada adianta os elogios demasiados que reduzem a visão e não permitem o avanço.

Destarte, sem a intenção de esgotar o assunto, mas sim de chamar a atenção para a necessidade de aprimorar os procedimentos da Lei dos Juizados, para que melhor cumpra os fins a que se propôs com credibilidade, nas diferentes comarcas deste País, este estudo traz algumas sugestões. Todas elas, sem sombra de dúvidas, merecem discussões apartadas; contudo, o presente trabalho não comporta tal apreciação sob pena de tornar-se demasiadamente delongado. Seguem, assim, algumas sugestões:

1. Visando a um melhor atendimento às partes litigantes e seus eventuais procuradores, percebe-se a necessidade de uma ampliação do número de funcionários cartorários; uma vez que com o aumento da demanda nos Juizados de cidades de médio e grande porte, pela sua natural facilitação de acesso à Justiça, faz com que a quantidade de funcionários seja inferior ao necessário para um atendimento mais célere e eficiente de seus jurisdicionados.

2. Investimentos na infra-estrutura dos Juizados, consoante a demanda em cada comarca.

3. Necessidade de um juiz exclusivo para atuação no Juizado, sob pena de que sendo titular de diferentes varas no Foro, a exemplo do que ocorre em muitas das cidades interioranas, acabe por engessar a prática do procedimento no Juizado onde atua, introduzindo neste, formalismos da justiça comum, os quais tanto se lutou para que fossem superados nas matérias de competência da Lei 9099/95.

4. Criação de mini-cursos gratuitos de aprimoramento dos estagiários interessados em atuar neste órgão, em razão de que muitos iniciam esta atividade nos primeiros semestres do curso de Direito.

5. Criação de uma Defensoria Pública de atuação exclusiva nos Juizados Especiais Cíveis, como já ocorre nos Criminais, tornado efetiva a aplicação da previsão do artigo $9^{\circ}, \S 1^{\circ}$ da Lei 9099/95. 
Estas são algumas, das sugestões existentes que visam melhorar a qualidade dos Juizados Especiais Cíveis. Entretanto, o presente trabalho não tem a pretensão de esgotar o assunto, buscando, dessa forma, incentivar o aprofundamento do conhecimento acerca desta matéria, com o intuito de colaborar com o avanço na prestação jurisdicional deste órgão.

\section{Considerações Finais}

Das reflexões acima realizadas, constata-se que os Juizados Especiais têm o intuito de oferecer a população mecanismos mais ágeis e eficientes para a solução dos conflitos. Dessa forma, a Lei 9099/95 representa para a sociedade uma nova perspectiva de acesso à prestação jurisdicional, possibilitando uma reaproximação do direito material com o direito processual, desafiando, com isso, o conservadorismo de alguns legisladores. Contudo, para que esta moderna construção não fique estagnada e o esforço de seus "arquitetos" não seja em vão, é imprescindível que os operadores do direito continuem empenhando-se para melhorar a prestação jurisdicional nos Juizados Especiais Cíveis; bem como possibilitar a expansão de seus princípios para a Justiça Comum, adaptando-a aos anseios da sociedade contemporânea.

Assim, da mesma maneira que Sísifo, luta-se para manter viva a consciência do homem ousado e desafiador nas dificuldades impostas pelos conservadores, os quais apesar de admitirem as necessidades de aprimorar a prestação jurisdicional, não procuram inovar seus pensamentos, permanecendo, portanto, presos ao rigorismo formal que engessa o judiciário como um todo.

Há de se ressaltar, ainda, que esta Lei, ao contrário do que pensam alguns doutrinadores, não afasta o direito processual do direito material. Pelo contrário, possibilita, através de seus princípios, superar o rigorismo formal, trazendo como primazia os princípios supra mencionados, visando a tutelar de maneira mais célere, justa e efetiva, o direito material.

Dessa forma, para se chegar ao alto da montanha, cabe a todos, operadores ou não do direito, a tarefa de exigir pensamento inovadores, os quais possibilitam prestigiar o Juizado e ao mesmo tempo apontar suas falhas, bem como indicar os melhores caminhos.

\section{Referências Bibliográficas:}

FUX, LUIZ. Manual dos Juizados Especiais Cíveis. Doutrina, prática, jurisprudência. Rio de Janeiro: Destaque, 1998. 
MARINONI, Luiz Guilherme; ARENHART, Sérgio Cruz. Manual do Processo de Conhecimento. $4^{\circ}$ ed. São Paulo: Revista dos Tribunais, 2005.

MÉNDEZ, Francisco Ramos. El mito de Sísifo y la ciencia procesal. Barcelona: Atelier. 2004.

Revista dos Juizados Especiais. $\mathrm{N}^{\circ}$ 34/35. A efetividade dos Juizados Especiais Cíveis e a questão do acesso à Justiça. Wilson Carlos Rodycz. Abril/Agosto 2002. Porto Alegre. Tribunal de Justiça - Estado do Rio Grande do Sul.

Revista dos Juizados Especiais. $\mathrm{N}^{\circ}$ 22. O acesso à Justiça e o Juizado Especial Cível. Rogério Leal e Mônica Hennig. Abril 1998. Porto Alegre. Tribunal de Justiça do Estado do Rio Grande do Sul.

Revista dos Juizados Especiais. №15. A conciliação nos Juizados Especiais. Dezembro 1995. Antônio Pessoa Cardoso. Porto Alegre. Tribunal de Justiça do Estado do Rio Grande do Sul.

SILVA, Ovídio A. Batista da. Processo e Ideologia: O paradigma racionalista. $1^{\circ} \mathrm{ed}$. Rio de Janeiro: Forense, 2004. 